\title{
Keterkaitan antara Pola Keterampilan Berpikir dengan Penguasaan Konsep Siswa pada Pembelajaran Strategi Metakognisi Berbantuan Thinking Map
}

\author{
Dyne Rizki Puspitasari, Lia Yuliati, Sentot Kusairi \\ Pendidikan Fisika, Pasacasarjana Universitas Negeri Malang \\ E-mail: dyne_pasundan@yahoo.com
}

Received 30-05-2014, Revised 01-07-2014, Accepted 08-08-2014, Published 31-10-2014

\begin{abstract}
The purpose of this research is to analyze relationship between thinking skill pattern and students' conceptual acquisition on metacognitive strategy assisted by thinking map. This mixed method research (embedded experimental design) was conducted at junior high school students and used conceptual acquisition test (posttest) and observation paper. The observation paper was used to analyze students' thinking skill pattern by using thinking map. The result of this research showed that students who had high thinking skill pattern reached high conceptual acquisition score too. This physics conceptual acquisition score showed students' cognitive process grade. Conclusion of this research is the relationship between thinking skill pattern and junior high school students' physics conceptual acquisition is exist.
\end{abstract}

Keywords: higher order thinking skill pattern, concept acquisition, metacognitive strategy, thinking map.

\section{ABSTRAK}

Penelitian ini bertujuan untuk menganalisis keterkaitan antara pola keterampilan berpikir dengan penguasaan konsep siswa pada pembelajaran strategi metakognisi berbantuan thinking map. Penelitian yang menggunakan mixed method desain embeded eksperimental ini dilakukan pada siswa SMP dengan instrumen berupa soal penguasaan konsep (postest) dan lembar observasi. Lembar observasi digunakan untuk menganalisis pola keterampilan berpikir siswa melalui thinking map yang dibuat oleh siswa di setiap akhir pembelajaran. Hasil penelitian menunjukkan siswa yang memiliki pola keterampilan berpikir tinggi juga mencapai sekor penguasaan konsep fisika yang tinggi. Sekor penguasaan konsep fisika tersebut juga menunjukkan tingkat proses kognitif siswa. Kesimpulan dari penelitian ini adalah adanya keterkaitan antara pola keterampilan berpikir dengan penguasaan konsep fisika siswa SMP.

Kata kunci: pola keterampilan berpikir tingkat tinggi, penguasaan konsep, strategi metakognisi, thinking map

\section{PENDAHULUAN}

Konsep fisika tidak mungkin terlepas dari pemahaman yang koheren terhadap aspek pengetahuan kualitatif dan kuantitatif. Pengetahuan kualitatif terdiri dari teori, hukum, dan fakta. Pengetahuan kuantitatif terdiri dari aturan, keterampilan, dan teknik ${ }^{[1]}$. Misalnya saat mempelajari hukum ke 2 Newton tentang gerak. Siswa mungkin hafal dengan bunyi 
hukum ke 2 Newton, tetapi belum tentu dapat mengoperasikan rumus $F=m \cdot a$ saat menemukan soal hitungan kinematika.

Berdasarkan fakta tersebut, diperlukan strategi pembelajaran yang dapat mengoptimalkan kemampuan peguasaan konsep fisika. Salah satu strategi pembelajaran tersebut adalah strategi pembelajaran metakognisi. Strategi pembelajaran metakognisi mengajarkan cara untuk merencanakan berbagai langkah pemecahan masalah, melakukan refleksi, dan mengevaluasi hasil, serta memodifikasi berbagai cara belajar yang dibutuhkan oleh siswa untuk mencapai pengetahuan baru yang lebih kompleks atau mencapai keterampilan berpikir tingkat tinggi ${ }^{[2,3,4,5]}$.

Penerapan strategi pembelajaran metakognisi merupakan upaya pemberdayaan kemampuan metakognisi siswa dalam belajar. Jika siswa sudah memiliki kemampuan metakognisi yang baik, maka keterampilan berpikir tingkat tinggi dan penguasaan konsepnya juga akan membaik $[2,4,5,6,7,8,9]$. Namun, belum ada penelitian yang membuktikan keterkaitan langsung antara keterampilan berpikir tingkat tinggi dengan penguasaan konsep siswa, khususnya pada pelajaran fisika. Penelitian yang telah dilakukan selama ini hanya mengungkapkan ketidak sesuaian antara tingkat pencapaian penguasaan konsep dengan pola berpikir siswa. Tetapi, pola berpikir siswa yang dideteksi selama ini masih menggunakan indikator berpikir deduktif-induktif ${ }^{[10]}$, pola berpikir logis-kreatif ${ }^{[11]}$, dan pola kemampuan berpikir kreatif-kritis-pemecahan masalahpengambilan keputusan ${ }^{[12,13]}$. Oleh karena itu, diperlukan penyelidikan pola berpikir siswa dengan menggunakan indikator Bloom karena mayoritas soal yang disusun guru di berbagai sekolah masih menggunakan indikator keterampilan berpikir tingkat tinggi tersebut.

Berdasarakan uraian tersebut, intergrasi thinking map dalam strategi pembelajaran metakognisi diperlukan untuk memudahkan siswa dalam mengorganisasi pengetahuan yang diterima sekaligus sebagai alat evaluasi proses kognitif. Thinking map mengajak siswa untuk mengungkapkan pemikiran dan ide sehingga guru akan melihat grafik representasi dari hasil pemikiran siswa tersebut ${ }^{[14,15,16]}$. Berbeda dengan grafik organizer lain, thinking map lebih mengutamakan strategi berpikir, fokus terhadap proses penemuan jawaban yang tepat, merupakan alat kontrol yang baik dalam menguasai materi pembelajaran di kelas, dan merupakan strategi belajar yang mampu menghubungkan konten dengan lebih bermakna ${ }^{[14,16]}$. Selanjutnya, pola keterampilan berpikir tingkat tinggi dapat diklasifikasikan berdasarkan visualisasi proses kognitif yang digambarkan oleh siswa melalui thinking map dengan menggunakan rubrik M.A.PP.E.R. yang telah dimodifikasi menggunakan indikator Bloom.

Lebih lanjut, penelitian ini bertujuan untuk mencari ada tidaknya keterkaitan antara pola keterampilan berpikir dengan penguasaan konsep fisika siswa. Dengan mengetahui keterkaitan ini guru diharapkan mampu memberikan antisipasi dan solusi yang tepat bagi perkembangan belajar siswa. Selain itu, hasil penelitian ini diharapkan dapat digunakan guru sebagai alternatif strategi pembelajaran fisika yang fokus terhadap pengembangan keterampilan berpikir dan penguasaan konsep siswa. 


\section{METODE}

Penelitian ini dilakukan menggunakan mixed methode desain embeded eksperimental. Penelitian dilakukan terhadap 22 siswa SMP Laboratorium UM. Instrumen penelitian yang digunakan adalah RPP dengan strategi metakognisi berbantuan thinking map, soal pretest postest untuk mengetahui penguasaan konsep fisika siswa sebelum dan sesudah diberi perlakuan, LKS untuk mendukung aktivitas belajar siswa, dan lembar obeservasi thinking map dengan rubrik M.A.PP.E.R untuk menemukan pola keterampilan berpikir tingkat tinggi.

Analisis data secara kuantitatif dilakukan terhadap data sekor penguasaan konsep fisika siswa dan sekor pola keterampilan berpikir siswa. Sekor pola keterampilan berpikir siswa didapatkan dari analisis semua thinking map yang dibuat siswa pada setiap tatap muka. Sedangkan analisis data secara kualitatif dilakukan untuk mencari keterkaitan antara pola keterampilan berpikir dengan penguasaan konsep siswa pada pembelajaran strategi metakognisi berbantuan thinking map.

\section{HASIL DAN PEMBAHASAN}

Berikut disajikan Tabel 1 tentang analisis keterkaitan pola keterampila berpikir tingkat tinggi dengan penguasaan konsep fisika siswa.

Tabel 1. Analisis Keterkaitan Pola Keterampila Berpikir Tingkat Tinggi dengan Penguasaan Konsep Fisika Siswa

\begin{tabular}{|c|c|c|c|c|c|c|c|c|c|c|c|c|c|c|c|c|c|c|c|c|c|}
\hline \multirow{2}{*}{$\begin{array}{l}\text { Nomor } \\
\text { Siswa }\end{array}$} & \multicolumn{18}{|c|}{ Nomor Soal } & \multirow[b]{2}{*}{$\begin{array}{l}\text { Total } \\
\text { Sekor }\end{array}$} & \multirow[b]{2}{*}{ Nilai } & \multirow{2}{*}{$\begin{array}{c}\text { Pola } \\
\text { keterampilan } \\
\text { Berpikir } \\
\text { Siswa }\end{array}$} \\
\hline & 1 & 2 & 3 & 4 & 5 & 6 & 7 & 8 & 9 & 10 & 11 & 12 & 13 & 14 & 15 & 16 & 17 & 18 & & & \\
\hline 1 & 0 & 1 & 1 & 1 & 1 & 1 & 0 & 1 & 1 & 1 & 1 & 0 & 1 & 1 & 1 & 1 & 0 & 1 & 14 & 77.8 & \\
\hline 2 & 1 & 1 & 1 & 1 & 1 & 1 & 0 & 1 & 1 & 1 & 1 & 1 & 1 & 1 & 1 & 1 & 0 & 1 & 16 & 88.9 & C5 \\
\hline 3 & 1 & 1 & 0 & 1 & 1 & 0 & 0 & 0 & 1 & 1 & 1 & 1 & 1 & 1 & 1 & 1 & 0 & 1 & 13 & 72.2 & $\mathrm{C} 4$ \\
\hline 4 & 1 & 1 & 1 & 1 & 1 & 1 & 1 & 0 & 1 & 1 & 1 & 1 & 1 & 1 & 1 & 0 & 1 & 1 & 16 & 88.9 & \\
\hline 5 & 1 & 1 & 1 & 1 & 1 & 1 & 1 & 1 & 1 & 1 & 1 & 1 & 1 & 1 & 1 & 1 & 1 & 1 & 18 & 100.0 & \\
\hline 6 & 1 & 1 & 1 & 0 & 1 & 1 & 0 & 1 & 1 & 1 & 1 & 1 & 1 & 1 & 0 & 1 & 1 & 1 & 15 & 83.3 & \\
\hline 7 & 1 & 0 & 1 & 1 & 1 & 1 & 1 & 1 & 1 & 1 & 0 & 1 & 0 & 1 & 0 & 0 & 0 & 0 & 11 & 61.1 & \\
\hline 8 & 1 & 1 & 1 & 0 & 0 & 1 & 1 & 1 & 1 & 0 & 1 & 1 & 0 & 1 & 0 & 1 & 1 & 1 & 13 & 72.2 & C3 \\
\hline 9 & 1 & 1 & 1 & 1 & 1 & 1 & 1 & 1 & 1 & 1 & 1 & 1 & 1 & 1 & 1 & 1 & 1 & 1 & 18 & 100 & C6 \\
\hline 10 & 1 & 1 & 0 & 1 & 1 & 1 & 0 & 1 & 0 & 1 & 1 & 0 & 1 & 1 & 0 & 1 & 0 & 1 & 12 & 66.7 & \\
\hline 11 & 1 & 1 & 0 & 1 & 0 & 1 & 0 & 1 & 1 & 0 & 1 & 1 & 0 & 1 & 1 & 0 & 0 & 1 & 11 & 61.1 & \\
\hline 12 & 1 & 1 & 1 & 1 & 1 & 0 & 0 & 1 & 1 & 1 & 1 & 0 & 1 & 1 & 1 & 0 & 0 & 1 & 13 & 72.2 & \\
\hline 13 & 1 & 0 & 1 & 1 & 1 & 1 & 1 & 0 & 0 & 0 & 1 & 1 & 1 & 1 & 0 & 1 & 1 & 0 & 12 & 66.7 & \\
\hline 14 & 1 & 1 & 0 & 1 & 1 & 0 & 0 & 1 & 1 & 1 & 1 & 1 & 1 & 0 & 1 & 1 & 0 & 1 & 13 & 72.2 & \\
\hline 15 & 1 & 1 & 0 & 0 & 0 & 0 & 0 & 1 & 0 & 0 & 0 & 0 & 1 & 1 & 0 & 0 & 0 & 1 & 6 & 33.3 & \\
\hline 16 & 1 & 0 & 1 & 1 & 1 & 1 & 1 & 0 & 1 & 0 & 1 & 0 & 1 & 1 & 1 & 0 & 1 & 0 & 12 & 66.7 & $\mathrm{C} 2$ \\
\hline 17 & 1 & 1 & 1 & 1 & 1 & 1 & 1 & 0 & 1 & 1 & 1 & 1 & 1 & 1 & 1 & 1 & 0 & 1 & 16 & 88.9 & \\
\hline 18 & 1 & 1 & 1 & 1 & 1 & 1 & 0 & 1 & 1 & 1 & 1 & 1 & 1 & 1 & 0 & 1 & 1 & 1 & 16 & 88.9 & \\
\hline 19 & 1 & 1 & 0 & 1 & 1 & 1 & 1 & 1 & 1 & 0 & 0 & 0 & 0 & 1 & 0 & 1 & 1 & 0 & 11 & 61.1 & \\
\hline 20 & 1 & 1 & 1 & 1 & 1 & 1 & 0 & 1 & 0 & 1 & 1 & 1 & 1 & 1 & 1 & 1 & 0 & 0 & 14 & 77.8 & \\
\hline 21 & 1 & 0 & 1 & 0 & 1 & 1 & 1 & 1 & 1 & 1 & 1 & 1 & 0 & 1 & 0 & 1 & 1 & 0 & 13 & 72.2 & \\
\hline 22 & 1 & 1 & 1 & 1 & 1 & 0 & 0 & 1 & 1 & 1 & 1 & 1 & 1 & 1 & 1 & 1 & 0 & 1 & 15 & 83.3 & \\
\hline $\begin{array}{c}\text { Tingkat } \\
\text { Kesulitan }\end{array}$ & $\mathrm{C} 1$ & C3 & $\mathrm{C} 4$ & $\mathrm{C} 2$ & $\mathrm{C} 2$ & $\mathrm{C} 4$ & C5 & C5 & $\mathrm{C} 4$ & C3 & C3 & $\mathrm{C} 4$ & $\mathrm{C} 2$ & $\mathrm{C} 4$ & $\mathrm{C} 4$ & $\mathrm{C} 4$ & C5 & C3 & Rata-1 & a kelas & \\
\hline
\end{tabular}


Siswa nomor 16 menunjukkan pola keterampilan berpikir rata-rata pada tingkatan C2. Kemampuan pemahaman yang baik tersebut didukung oleh prestasi belajar siswa yang mencapai nilai rata-rata 75 . Siswa nomor 16 ini ternyata tidak hanya mampu mengerjakan soal yang memiliki taraf kesulitan C2 tetapi juga terbukti mampu mengerjakan beberapa soal yang memiliki taraf kesulitan yang lebih tinggi. Berdasarkan hasil wawancara, siswa nomor 16 mengaku, "belajar fisika dengan strategi metakognisi dan thinking map memudahkan saya dalam belajar, khususnya karena ada thinking map untuk merangkum materi". Temuan dan wawancara tersebut senada dengan hasil temuan ${ }^{[15]}$ yang menyimpulkan bahwa penggunaan thinking map dapat membantu siswa untuk menemukan hubungan yang bermakna antara materi yang dipelajari dengan isi yang dimaksud.

Siswa nomor 3 dan 2 menunjukkan pola yang serupa dengan siswa nomor 16. Siswa nomor 3 menunjukkan pola keterampilan berpikir rata-rata pada tingkatan $\mathrm{C} 4$ dengan prestasi belajar 77,8. Siswa tersebut mengalami kesalahan saat mengerjakan soal dengan tingkat kesulitan C4 sebanyak 3 kali, dan C5 sebanya 5 kali. Siswa nomor 2 menunjukkan pola keterampilan berpikir rata-rata pada tingkatan C5 dengan prestasi belajar 88,9. Siswa nomor 2 mengalami kesalahan saat mengerjakan soal C5 sebanyak 4 kali. Kedua siswa ini menunjukkan mayoritas kesalahan dilakukan pada soal-soal dengan tingkat kesulitan yang sama dan lebih tinggi dari keterampilan berpikir yang dimiliki.

Siswa nomor 8 menunjukkan pola keterampilan berpikir rata-rata pada tingkatan C3. Meskipun kemampuan menerapkan teori cukup baik, namun prestasi belajar siswa tersebut hanya mencapai 69,5. Dari hasil analisis postest yang telah dikerjakan, ternyata siswa nomor 8 melakukan kesalahan untuk semua soal dengan tingkat kesulitan C2 dan beberapa soal yang memiliki tingkat kesulitas di atas C3. Jika kesalahan yang dibuat siswa untuk semua soal dengan tingkat kesulitan C3 atau diatasnya dianggap wajar maka tidak untuk soal dengan tingkat kesulitan C2. Maka dari itu, peneliti menelusuri soal-soal yang tidak dapat dijawab dengan benar oleh siswa nomor 8. Berikut beberapa soal dengan tingkat kesulitan $\mathrm{C} 2$ (pemahaman) yang tidak dapat dijawab dengan benar oleh siswa nomor 8 .

1. Sebuah benda akan berada dalam keadaan setimbang apabila dua buah gaya yang bekerja pada benda ....
A. sama besar dan searah
B. sama besar dan berlawanan arah
C. tidak sama besar dan searah
D. tidak sama besar dan berlawanan arah

2. Ketika kamu berada dalam kendaraan yang diam. Kemudian tiba-tiba kendaraan tersebut bergerak, tubuhmu akan terasa seperti terdorong ke belakang. Hal ini terjadi karena....
A. tubuhmu cenderung mempertahankan posisinya yang diam
B. tubuhmu cenderung mengikuti gerakan kendaraan
C. tubuhmu cenderung melawan gerakan kendaraan
D. tubuhmu tidak mempunyai energi untuk bergerak ke depan 
Siswa nomor 8 menjawab A untuk soal nomor 1, karena menurut siswa tersebut almari yang akan roboh harus ditahan dengan gaya yang besar dan searah agar tetap diam serta tidak jatuh. Pernyataan ini mungkin merupakan pengalaman siswa sehari-hari. Akan tetapi siswa tersebut melupakan bahwa ada konsep gaya berat yang harus dilawan dengan gaya tahan terhadap almari agar almari tetap dalam kondisi diam dan seimbang. Selanjutnya, siswa nomor 8 menjawab D untuk soal nomor 2, karena menurut siswa tersebut tubuh sedang dalam kondisi tidak siap dan cenderung tidak memiliki energi untuk melawan gerakan mobil saat di-gas. Tanpa memperhitungkan adanya sifat lembang suatu benda, siswa nomor 8 menjawab, "Tubuh kan tidak akan bergerak kebelakang kalau tubuh bersiap-siap dan bertahan pada sandaran kursi untuk melawan gerakan mobil yang sedang di-gas, Bu?".

Terakhir, siswa nomor 9 menunjukkan pola keterampilan berpikir rata-rata pada tingkatan C6 dengan prestasi belajar 100. Siswa nomor 9 tidak mengalami kesulitan saat memahami materi belajar. Setelah dilakukan penelusuran dengan cara wawancara kepada siswa nomor 9, peneliti mendapatkan temuan bahwa siswa yang bersangkutan mengaku selalu mencoba menerapkan dengan baik strategi metakognisi yang diajarkan guru untuk menguasai materi fisika. Siswa nomor 9 selalu mempersiapkan materi yang akan dipelajari dengan baik dan melakukan berbagai evaluasi terhadap pemahamannya, salah satunya dengan membuat thinking map dalam berbagai jenis.

\section{KESIMPULAN}

Kesimpulan dari penelitian ini adalah tingkat keterampilan berpikir siswa benar-benar telah menggambarkan kemampuan proses kognitif siswa yang sesungguhnya. Siswa yang menguasai keterampilan berpikir tingkat tinggi terbukti telah melampaui keterampilan berpikir tingkat rendah atau keterampilan berpikir tingkat dasar, termasuk kemampuan untuk memahami dan menguasai konsep. Selain itu, siswa yang memiliki keterampilan berpikir tingkat tinggi yang baik akan berdampak baik pula pada kemampuan untuk menguasai konsep, mengambil makna, mengevaluasi, bernalar, berafikasi, menganalogi konsep, hingga memecahkan masalah-masalah baru (novel problem).

Perlu dilakukan penelitian serupa dengan indikator keterampilan berpikir tingkat tinggi lainya, seperti kemampuan berpikir kritis. Selain itu, penelitian diharapkan dilakukan dalam rentangan waktu yang lebih lama agar data yang diperoleh lebih detail. Selain itu, perlu dilakukan pengawasan yang ketat pada pemahaman konsep siswa agar tidak terjadi kesalahan konsep seperti siswa nomor 8 .

\section{UCAPAN TERIMAKASIH}

Ucapan terima kasih kami haturkan kepada kepala sekolah SMP Laboratorium UM dan ibu/bapak dosen prodi pendidikan fisika pascasarjana UM yang telah memberikan dukungan dan bimbingan selama penelitian. 


\section{DAFTAR PUSTAKA}

1 Yuliati, L. 2008. Model-Model Pembelajaran Fisika “Teori dan Praktek”.Malang: Lembaga Pengembangan Pendidikan dan Pengajaran (LP3) Universitas Negeri Malang.

2 Nuryana, M., dan Sugiarto, B. 2012. Hubungan Keterampilan Metakognisi dengan Hasil Belajar Siswa Pada Materi Reaksi Reduksi Oksidasi (Redoks) Kelas X-1 SMA Negeri 3 Sidoarjo. Unesa Journal of Chemical Education, 1 (1): 83-91.

3 Nashon. S. M., dan Nielsen, W. 2011. Connecting Student Self-Regulation, Metacognition and Learning to Analogical Thinking in A Physics Problemsolving Discourse. International Research Journals. 1 (5): 68 - 83.

4 Sastrawati, E., Rusdi, M., dan Syamsurizal. 2011. Problem based Learning, strategi Metakognisi, dan Metermapilan Berpikir Tingkat Tinggi Siswa. Tekno Pedagogi, 1 (2): $1-14$

5 Lucky, A. dan Mulyanratna, M. 2012. Penerapan Strategi Belajar Metakognitif dalam Meningkatkan Kualitas Belajar Siswa Pada Materi Cahaya di Kelas VIII SMP Negeri 1 Mojokerto. Jurnal FMIPA Unesa. 321-329.

6 Corebima, A. D. 2006. Pembelajaran Biologi yang Memberdayakan Kemampuan Berpikir Siswa. Makalah disajikan pada Pelatihan Strategi Metakognitif pada Pembelajaran Biologi untuk Guru-Guru Biologi SMA di Kota Palangkaraya, 23 Agustus 2006.

7 Warouw, Z. W. M. 2010. Pembelajaran Reciprocal Teaching dan Metakognitif (RTM) yang Memberdayakan Keterampilan Metakognitif dan Hasil Belajar Biologi Siswa SMP. Jurnal Ilmu Pendidikan, 17 (2): 158-167.

8 Sirmac1, N., dan Tuncer, T. 2013. The Effect of Metacognition Strategies Applied in $7^{\text {th }}$ Grade Mathematics Course "Permutation and Probability" Subject on Student's Achievement, Metacognitive Skills, Attitudes and Permanence. Universal Journal of Education and General Studies. 2 (3): 71-78.

9 Ciascai, L., dan Haiduc, L.2011. Metacognitive Strategies that Romanian Pupils Use when Reading Science Textbooks. International Conference on Social Science and Humanity IPEDR.5(2) : 389-392.

10 Julianto, E., Hartono, dan, Wiyanto. 2010. Pembelajaran Fisika untuk Menumbuhkan Kemampuan Berpikir Hipotetikal Deduktif pada Siswa SMA. Jurnal Pendidikan Indonesia. 7: 17-22.

11 Mustami, M. K. 2007. Pengaruh Model Pembelajaran Synectics dipadu Mind Maps terhadap Kemampuan Berpikir Kreatif, Sikap Kreatif, dan Penguasaan Konsep Biologi. Lentera Pendidikan. 10 (2): 173-184.

12 Santoso. 2009. Pengaruh Penggunaan Laboratorium Riil dan Laboratorium Cirtuil pada Pembelajaran Fisika ditinjau dari Kemampuan Berpikir Kritis Siswa. Tesis tidak diterbitkan. Universitas Sebelas Maret Surakarta.

13 Sudarmin. 2012. Meningkatkan Kemampuan Berpikir Tingkat Tinggi Mahasiswa Melalui Pembelajaran Kimia Terintegrasi Kemampuan Generik Sains. Varia Pendidikan. 24 (1): 97-103.

14 Hyerle, D. N. dan Williams, K. Bifocal Assessment in the Cognitive Age: Thinking Maps for Assessing Content Learning and Cognitive Processes. The New Hampshire Journal of Education, 2010, pp. 32-38. 
15 Long, D., dan Carlson, D. 2011. Mind the Map: How Thinking Maps Affect Student Achievement. Networks, vol 2, no. 13, 2011, pp. 1-7.

16 Costa, A. L. dan Kallick, B. 2000. Habit of Mind: Activating \& Engaging. USA: ASCD. 